\title{
Nickel spiking to improve the methane yield of sewage sludge
}

\author{
Tsapekos, Panagiotis; Alvarado-Morales, Merlin; Tong, Juan; Angelidaki, Irini
}

Published in:

Bioresource Technology

Link to article, DOI:

10.1016/j.biortech.2018.09.136

Publication date:

2018

Document Version

Peer reviewed version

Link back to DTU Orbit

Citation $(A P A)$ :

Tsapekos, P., Alvarado-Morales, M., Tong, J., \& Angelidaki, I. (2018). Nickel spiking to improve the methane yield of sewage sludge. Bioresource Technology, 270, 732-737. https://doi.org/10.1016/j.biortech.2018.09.136

\section{General rights}

Copyright and moral rights for the publications made accessible in the public portal are retained by the authors and/or other copyright owners and it is a condition of accessing publications that users recognise and abide by the legal requirements associated with these rights.

- Users may download and print one copy of any publication from the public portal for the purpose of private study or research.

- You may not further distribute the material or use it for any profit-making activity or commercial gain

- You may freely distribute the URL identifying the publication in the public portal 


\section{Nickel spiking to improve the methane yield of sewage sludge}

Panagiotis Tsapekos ${ }^{\mathrm{a}}$, Merlin Alvarado-Morales ${ }^{\mathrm{a}}$, Juan Tong ${ }^{\mathrm{b}}$ and Irini Angelidaki*

${ }^{a}$ Department of Environmental Engineering, Technical University of Denmark, Kgs.

Lyngby, DK-2800, Denmark

${ }^{b}$ Department of Water Pollution Control, Research Center for Eco-Environmental

Sciences, Chinese Academy of Sciences, Beijing 100085, China

${ }^{*}$ Corresponding author:

Irini Angelidaki, Department of Environmental Engineering, Technical University of Denmark, Bld 115, 2800 Lyngby Denmark

E-mail: iria@env.dtu.dk, Tel.: +4545251429; fax: +4545932850 


\begin{abstract}
The presence of micro-nutrients can be stimulatory for the anaerobic digestion (AD) of hardly degradable wastes and thus, improve process performance. Among the essential trace elements, nickel is involved in multiple important enzymes necessary for efficient AD. The present study investigates the effect of nickel spiked sewage sludge on batch and continuous mode operation. Metal spiking was conducted in the form of nanoparticles (Ni-NPs) and salt $\left(\mathrm{NiCl}_{2} \cdot 6 \mathrm{H}_{2} \mathrm{O}\right)$. Results from batch assays showed that $5 \mathrm{mgNi}-\mathrm{Salt} / \mathrm{kgVS}$ in the presence of Nitrilotriacetic acid (NTA) enhanced the methane yield by 10\% compared to the untreated sample. The impact of Ni-NPs in the AD process was also positive, but slightly lower compared to the effect of $\mathrm{NiCl}_{2} \cdot 6 \mathrm{H}_{2} \mathrm{O}$. The stimulatory impact of $\mathrm{Ni}$ was also revealed in continuously fed digester boosting the methane yield by $\sim 8 \%$. Overall, the improved methane production indicated that methanogenic archaea were favoured by the simultaneous supplementation of Ni and NTA.
\end{abstract}

\title{
Keywords
}

Anaerobic digestion; Sludge; Trace elements; Nickel; Nitrilotriacetic acid (NTA)

\section{Introduction}

The building blocks for the microbiome of the anaerobic digestion (AD) process can be distinguished at macro- (e.g. Carbon, Oxygen, Hydrogen, Nitrogen, Sulfur) and microelements (e.g. Cobalt, Copper, Molybdenum, Selenium, Nickel, Zinc, Tungsten) (Roussel et al., 2018). The knowledge of macro-elements content into the feedstock is crucial in order to avoid common operational problems related to e.g.: 1) ammonia or sulfide inhibition incidents due to the increase of added nitrogen or sulfur, respectively; 2) overloading or starvation conditions due to the fed amount of organic carbon. On the other hand, the way that each 
trace element (TE) affects the AD process is rather complex. The intricacy of AD renders extremely difficult to precisely understand the role of micronutrients because the effects of TEs easily shift from stimulatory to inhibitory. Unique microbial communities with alternating nutritional needs are established into dissimilar $\mathrm{AD}$ environments due to the variability of parameters as substrates' characteristics and/or operational conditions. Hence, the TEs do not influence in a constant pattern the multivariable and complex AD environments (Banks and Heaven, 2013). However, the role of specific TE to enhance microbial growth and activity has been previously defined to some extent in the literature (Bougrier et al., 2018; Demirel and Scherer, 2011; Romero-Güiza et al., 2016).

On this frame, nickel (Ni) has an important role for a well-performing methanogenesis and is considered to be among the most important TEs (Hu et al., 2008a; Vintiloiu et al., 2013). Specifically, Ni is involved into the expression of enzymes as CO dehydrogenase/acetyl-CoA synthase (Methanogens/Homoacetogens) and Methyl-CoM-reductase (Methanogens) (Fournier and Gogarten, 2008; Ko et al., 2018; Romero-Güiza et al., 2016). Especially for the later one, the presence of $\mathrm{Ni}$ is essential as it is the central atom of the complex coenzyme F430 (Prakash et al., 2014). Regarding methanogenesis, stimulatory effects were previously reported in a range from 0.03 to $27 \mathrm{mg}-\mathrm{Ni} / \mathrm{L}$ (Romero-Güiza et al., 2016). On another perspective, a concentration of 8 to $10 \mathrm{mg}-\mathrm{Ni} / \mathrm{kgTS}$ was found to be extremely beneficial for the microbiome (Vintiloiu et al., 2013).

Nevertheless, the optimum dosage of TE cannot be drawn through a simplified consideration, in which the sole influencing factor is the metal's concentration. For instance, the presence of chelating agents affects markedly the bioavailability of TEs for the anaerobic microbes (Serrano et al., 2017). The importance of chelating agents relies on the fact that they can replenish losses or low concentrations of TEs by avoiding the precipitation and control the limited metal availability (Flora and Pachauri, 2010). Organic agents as citric acid, 
nitrilotriacetic acid (NTA) and ethylenediaminetetraacetic acid (EDTA) have been previously examined as $\mathrm{Ni}$ chelators in $\mathrm{AD}$ process increasing the methane production from 10 to $49 \%$ (Hu et al., 2008b, 2008a; Vintiloiu et al., 2013). However, the aforementioned results are reported in limiting or unadapted conditions, in which the desired effects of both $\mathrm{Ni}$ and Nichelators are relatively easily to be detected. On the contrary, the positive role of metal additives to stimulate the methanation process of an adapted $\mathrm{AD}$ environment operated for a long period is still challenging.

The TEs are traditionally supplemented into the digesters in their corresponding salt form. However, the sluggish dissolving rate is still a challenge and therefore a potentially limited availability of metal ions can subsequently decrease the enzymatic activity. On this topic, nanotechnology appears as a scientific advancement to potentially overcome the challenge (Abdelsalam et al., 2016). Nanoparticles (NPs) can rapidly penetrate the cell walls and speed up the TEs uptake and metabolism. The high surface area, increased adsorption, dissolution and dispersion are unique characteristics that NPs possess (Gelperina et al., 2005).

The main objective of the present study was to investigate the effect of two different nickel sources on the biogas production from waste activated sludge. The role of Ni form was assessed by examining the addition of Ni-NPs and -salts in batch assays. To validate the results in more realistic conditions, continuous mode experiments were also conducted. Emphasis was given to increase TE availability via the addition of the chelating agent. Inoculum and substrate were obtained by the same full-scale facility in order to evaluate the effect of additives in an adapted microbial community.

\section{Materials and methods}

\subsection{Characteristics of inoculum and substrate}

Inoculum and sewage sludge were collected from Lynetten Wastewater Treatment plant 
(WWTP) - that operates under mesophilic conditions - in the greater Copenhagen area in Denmark. The effluent was placed in an incubator at $37 \pm 1{ }^{\circ} \mathrm{C}$ for one week before usage to remove the background methanation activity. The sewage sludge consisted of $50 \%$ primary and 50\% secondary sludge (v/v) and was collected from the same WWTP. The main characteristics of the inoculum and sewage sludge used in this work are given in Table S1.

\subsection{AD experiments}

Biochemical Methane Potential (BMP) assay was carried out to define the effect of $\mathrm{Ni}$ addition on the anaerobic biodegradability of sewage sludge as previously described by (Khoshnevisan et al., 2018). The extra $\mathrm{Ni}$ was added in the form of $\mathrm{NPs}$ and $\mathrm{NiCl}_{2} \cdot 6 \mathrm{H}_{2} \mathrm{O}$. The effect of $\mathrm{Ni}$ forms was examined at two final concentrations (i.e. 5 and $10 \mathrm{mg}-\mathrm{Ni} / \mathrm{kgVS}$ ) including the already available metal and at the absence or at the presence of a chelating agent (i.e. $2 \mathrm{mg}-\mathrm{NTA} / \mathrm{L}$ ). The size of Ni-NPs was lower than $100 \mathrm{~nm}$.

The lab-scale CSTR had a total and working volume of 2.3 and $2.0 \mathrm{~L}$, respectively. The CSTR was operated at mesophilic conditions $\left(37 \pm 1^{\circ} \mathrm{C}\right)$ heated with a silicone thermal jacket. The hydraulic retention time (HRT) was set at 20 days by daily supply of $100 \mathrm{~mL}$ sewage sludge and the organic loading rate (OLR) was $2.9 \mathrm{gVS} / \mathrm{L} / \mathrm{d}$. During the first period (0-20 days), the CSTR was fed with pure sewage sludge. Subsequently, at $21^{\text {st }}$ day of operation, external Ni source was injected to the CSTR as a single pulse to achieve the predetermined target of TE concentration. During the second period (21-60 days), the CSTR was fed with Ni spiked sewage sludge to maintain the Ni content at the desired value. The added amount of Ni, for both CSTR and feedstock, was calculated based on the results from the batch assays. During the whole experimental period, gas and liquid samples were taken twice a week to determine methane concentration, $\mathrm{pH}$ and VFA. The daily biogas volume was monitored by the liquid displacement method. 


\subsection{Analytical Methods}

Alkalinity, $\mathrm{pH}$, total solids (TS), volatile solids (VS) and chemical oxygen demand (COD) based on previous study (Tsapekos et al., 2017). Volatile fatty acids (VFA) and methane content were monitored using gas chromatography GC-TRACE 1310 and GC-TRACE 1300 of Thermo Scientific, respectively, as previously described by Khoshnevisan et al. (2018). Methanogenic enzymatic activity (i.e. Coenzyme $\mathrm{F}_{420}$ ) was assayed adapting the classic spectrophotometric method (Miao et al., 2013) using a Synergy Mx multimode microplate reader (BioTek Instruments, Inc., USA). The autofluorescence was measured at an excitation wavelength of $425 \mathrm{~nm}$ and an emission wavelength of $472 \mathrm{~nm}$. The TEs in inoculum and sewage sludge were analyzed by inductively coupled plasma with optical emission spectrometry (ICP-OES). For all analysis triplicate samples were measured.

\subsection{Kinetic models of methane production}

The kinetics of biomethanation process was modelled using first-order kinetics and modified Gompertz model equations. Focusing on hydrolysis, first-order kinetics was used, Eq. (1):

$$
M(t)=M_{0} \times(1-\exp (-K t))
$$

where, $M(t)$ is the produced methane $\left(\mathrm{NmLCH}_{4} / \mathrm{gVS}\right)$ over digestion time $t$ (days), $M_{0}$ is the maximum methane achieved potential $\left(\mathrm{NmLCH}_{4} / \mathrm{gVS}\right), K$ is the first-order disintegration rate constant (1/day).

In addition, the modified Gompertz equation was used to simulate the biomethanation process at the batch assays according to Eq. (2):

$$
M(t)=M_{0} \times \exp \left\{-\exp \left[\frac{R_{\max } \times e}{M_{0}}(\lambda-t)+1\right]\right\}
$$

where, $M(t)$ is the accumulated methane over time $\left(\mathrm{NmLCH}_{4} / \mathrm{gVS}\right)$, parameter $M_{0}$ is the 
final methane yield $\left(\mathrm{NmLCH}_{4} / \mathrm{gVS}\right), R_{\max }$ is the maximum methane production rate $\left(\mathrm{NmLCH}_{4} / \mathrm{gVS} / \mathrm{d}\right), \lambda$ is the lag phase (days), $t$ is the duration of the incubation period (days) and $e$ is Euler's number (2.7183).

\subsection{Statistical analysis}

One-way analysis of variance (ANOVA) followed by Tukey post hoc test $(p<0.05)$ was carried out to reveal the statistically significant differences among the treatments with the software OriginPro, version 9.0.0 (Corporation, Northampton, MA). The prediction accuracy of the non-linear regression models was estimated through the coefficient of determination $\left(R^{2}\right)$ and Standard Error (SE).

\section{Results and Discussion}

\subsection{Effect of nickel spiking on pH, COD, VFA and $\mathrm{CH}_{4}$ development in batch assays}

To begin with, $\mathrm{pH}$ values did not differ significantly $(\mathrm{p}>0.05)$ among all treatments on the fifth day of the incubation period (Table 1). The absence of remarkable differences was attributed to the fact that high amount of anaerobic inoculum was used and hence, the batch reactors were provided with high buffer capacity (Tsapekos et al., 2017). Similarly, negligible differences were detected through the alkalinity and COD measurements from samples taken in the middle of the experimental period. Intermediates products were produced and simultaneously, were further metabolized into methane leading to limited differences on COD degradation/accumulation. In this context, high and insignificantly different $(p>0.05)$ hydrolysis rates were observed for all the examined Ni additives' scenarios (Table S2), whose output is in accordance with the aforementioned COD measurements. While nickel is involved in the enzymatic hydrolysis of urease (Dixon et al., 1980), the solubilization of organic matter was not markedly stimulated at none of the examined scenarios. Especially for 
NPs tests, despite the fact that the metabolic intermediates and key enzyme secretions are boosted by specific nanopowder characteristics (e.g high surface area), the additives did not stimulate the excretion of fully active urease to further or quicker depolymerize the sewage sludge based on the experimental observations.

Likewise, statistically insignificant $(\mathrm{p}>0.05)$ differences were observed for the lag phases among all tests (Table S2). The result is easily explained by the fact that the microbial communities were well-adapted in the used substrate. Hence, the initially hydrolyzed monomers and the subsequently produced VFA were rapidly consumed by acidogenic and methanogenic communities, respectively. Hence, an adaptation period was not needed. The organic matter share of inoculum was higher than substrate's value (i.e. inoculum to substrate ratio of 1.5) to ensure that an enriched culture was provided in order to successfully metabolize the sludge and avoid acidification incidents. Focusing on lag phase decrease, an unadapted community or an adapted community at limiting conditions could have enlighten further the effects of Ni-forms in the initial AD steps.

In addition, accumulation of the majority of intermediates (e.g. propionic, butyric, isobutyric, valeric, iso-valeric and hexanoic acids) was not observed, showing that a wellperforming process was conducted. On the contrary, a clear difference was observed in terms of VFA accumulation. Specifically, all the Ni-treated samples had markedly lower acetate concentrations compared to the untreated experimental set. Since Ni supplementation could boost the expression of acetyl-coenzyme A synthetase (Fournier and Gogarten, 2008) -i.e. Wood-Ljungdahl pathway coupled to methanogenesis -, carbon monoxide dehydrogenase and methyl-S-CoM enzymes - i.e. methanogenesis via methanol acetate and $\mathrm{H}_{2} / \mathrm{CO}_{2}$, the low concentrations of accumulated acetate can be considered as an indirect indication that the methanogenic activity was stimulated by Ni supplementation. 
Regarding methane production, the positive impact of $\mathrm{Ni}$ addition was revealed in most of the examined scenarios (Fig. 1; Table 1). The highest methane yield enhancement $(\sim 10 \%)$ was achieved adding $5 \mathrm{mgNi}-\mathrm{Salt} / \mathrm{kgVS}$ along with $2 \mathrm{mg}-\mathrm{NTA} / \mathrm{L}$ (Fig. 1a). Similar result was also obtained when the double concentration of $\mathrm{Ni}$ was added using $\mathrm{NiCl}_{2}$ in the presence of the chelator $(\sim 8 \%, \mathrm{p}>0.05)$. Indeed, the results obtained in this work are in agreement with recent studies that examined the effects of similar Ni forms on the AD. Chen et al. (2008) reported that the $\mathrm{AD}$ of sludge was stimulated by the addition of $5.0 \mathrm{mg}-\mathrm{Ni} / \mathrm{L}-\mathrm{in}$ the form of $\mathrm{NiCl}_{2} \cdot 6 \mathrm{H}_{2} \mathrm{O}-$ after $6 \mathrm{~h}$ and then in a significant stimulation of methane production after $24 \mathrm{~h}$. In another study of Abdelsalam et al. (2017); the methane yield of livestock slurry, spiked with $1.0 \mathrm{mg}-\mathrm{Ni} / \mathrm{L}$ using $\mathrm{NiCl}_{2}$ as a source, resulted in $\sim 4 \%$ higher than the obtained value using Ni-NPs. On top of this, nano-sized materials can be strongly bound with various organic and inorganic fractions limiting the availability for the methanogenic populations. Hence, the slightly limited stimulating effect of Ni-NPs compared to Ni-Salt can be attributed to a potential antagonism with ligands that led to partial precipitation of metals. As for the effect of NTA, it was concluded that the addition of a chelator has a positive effect on methane production. Due to its supplementation, most of Ni could have formed soluble organic complexes with certain amino acids and so, the bioavailability for methanogens was increased, avoiding the precipitation of sulphides, carbonates or phosphates (Hu et al., 2008a). Overall, the more distinct impacts in methanogenesis compared to the previously AD steps can be ascribed to the fact that nickel is more important for the growth of archaeal than the bacterial species; as it contributes to retain their cell membranes and boost structural stability (Vintiloiu et al., 2013). In addition to that, $\mathrm{Ni}$ is an essential component of the low molecular weight coenzyme $\mathrm{F}_{430}$ which uses two coenzymes -methyl thio-ether-methyl-coenzyme M and the thiol coenzyme B -as substrates for the production of methane in all methanogens 
(Chen et al., 2016). Hence, a stimulatory effect can be more easily observed when added in appropriate levels (Roussel et al., 2018).

\subsection{AD of nickel spiked sludge at continuous mode operation}

The most effective Ni supplementation identified by BMP assays (i.e. $5 \mathrm{mgNi}-\mathrm{Salt} / \mathrm{kgVS}$ and $2 \mathrm{mg}-\mathrm{NTA} / \mathrm{L}$ ) was further examined in CSTR mode (Fig. 2). Initially, the CSTR was fed with sewage sludge until reaching steady conditions with no significant fluctuations $(p>0.05)$ in terms of $\mathrm{pH}$, VFA, biogas and methane for ten consecutive days. At the end of the first period, the bioenergy yield was $300 \pm 11 \mathrm{NmLCH}_{4} / \mathrm{gVS}$ (Fig. 2a), corresponding to $56 \%$ of the theoretical maximum value based on biomass chemical composition.

At the end of the first HRT, feedstock and CSTR were supplemented with the corresponding amount of $\mathrm{Ni}$ as revealed by BMP tests. In accordance with batch assays, $\mathrm{pH}$ values were relatively unchanged $(7.23 \pm 0.05)$; and on the other hand, the positive impact of Ni on methane output was also revealed in continuous mode operation. At the second steadystate, the methane yield was $8 \%$ higher compared to Period I. The achieved methane yield (324 $\pm 8 \mathrm{NmLCH}_{4} / \mathrm{gVS}$ ) corresponded to $76 \%$ of the practical BMP value, which is acceptable as $70-90 \%$ of the yield obtained in BMP test is expected in CSTR mode (Tsapekos et al., 2018). Comparing the practical yield with the maximum theoretical based on COD, the nickel spiked sludge has $60 \%$ anaerobic biodegradability. It worths highlighting that process efficiency was markedly acceptable, as about $40-50 \%$ biodegradability is expected for sludge based-AD (Grosser and Neczaj, 2016).

In addition, the VFA concentrations were slightly lower than Period I (Fig. 2b). For instance, acetate concentrations were decreased to values lower than $0.3 \mathrm{~g} / \mathrm{L}$, which can be related to the improved performance of methanogenic microorganisms ( $\mathrm{Yu}$ et al., 2016). On top of this, the highest $\mathrm{F}_{420}$ activity was observed during the second experimental period. 
Specifically, the highest relative activity was observed on the 25 th day of operation, when the accumulated intermediates started to decrease and the methane production has already lifted up on the increased level compared to Period I (Fig. 2). At steady-state conditions of Period I and II the $\mathrm{F}_{420}$ activities were $70 \%$ and $88 \%$ of the highest, respectively. Thus, the lowest relative activity was detected at limited $\mathrm{Ni}$ content. Hence, the methanogenic enzymatic activities consisted perfectly with the detected experimental observations. Overall, the steady operation of CSTR fed with sewage sludge supplemented with trace amounts of $\mathrm{Ni}$, advocate the positive impact of the examined micro-nutrient on an already stable and adapted AD process.

\section{Conclusions}

The present study demonstrated that nickel spiked sewage sludge can lead to improved anaerobic digestion. In addition, the bioavailability of trace metals for the methanogenic archaea was boosted by supplementing the nickel spiked sludge with Nitrilotriacetic acid (NTA). Spiking trace metals in the form of salt $\left(\mathrm{NiCl}_{2} \cdot 6 \mathrm{H}_{2} \mathrm{O}\right)$ had a clear stimulatory effect. Specifically, $5 \mathrm{mgNi}$-Salt/kgVS complexed with NTA can be associated with increased methane yield up to $10 \%$. Furthermore, the improved biodegradation efficiency was similar at different reactors configurations (i.e. batch and continuously fed digesters).

\section{Acknowledgement}

We acknowledge BIOFOS Renseanlæg Lynetten for inoculum and sludge providing. Juan Tong would like to thank for the financial support from China Scholarship Council.

\section{References}

Abdelsalam, E., Samer, M., Attia, Y.A., Abdel-Hadi, M.A., Hassan, H.E., Badr, Y., 2017. Effects of $\mathrm{Co}$ and $\mathrm{Ni}$ nanoparticles on biogas and methane production from anaerobic 
digestion of slurry. Energy Convers. Manag. 141, 108-119.

Abdelsalam, E., Samer, M., Attia, Y.A., Abdel-Hadi, M.A., Hassan, H.E., Badr, Y., 2016. Comparison of nanoparticles effects on biogas and methane production from anaerobic digestion of cattle dung slurry. Renew. Energy 87, 592-598.

Banks, C.J., Heaven, S., 2013. Optimisation of biogas yields from anaerobic digestion by feedstock type, in: The Biogas Handbook: Science, Production and Applications. pp. $131-165$.

Bougrier, C., Dognin, D., Laroche, C., Gonzalez, V., Benali-Raclot, D., Cacho Rivero, J.A., 2018. Anaerobic digestion of Brewery Spent Grains: Trace elements addition requirement. Bioresour. Technol. 247, 1193-1196.

Chen, J.L., Steele, T.W.J., Stuckey, D.C., 2016. Stimulation and Inhibition of Anaerobic Digestion by Nickel and Cobalt: A Rapid Assessment Using the Resazurin Reduction Assay. Environ. Sci. Technol. 50, 11154-11163.

Chen, Y., Cheng, J.J., Creamer, K.S., 2008. Inhibition of anaerobic digestion process: a review. Bioresour. Technol. 99, 4044-64.

Demirel, B., Scherer, P., 2011. Trace element requirements of agricultural biogas digesters during biological conversion of renewable biomass to methane. Biomass and Bioenergy $35,992-998$.

Dixon, N.E., Gazzola, C., Asher, C.J., Lee, D.S.W., Blakeley, R.L., Zerner, B., 1980. Jack bean urease (EC 3.5.1.5). II. The relationship between nickel, enzymatic activity, and the "abnormal" ultraviolet spectrum. The nickel content of jack beans. Can. J. Biochem. 481-488. https://doi.org/10.1139/o80-063

Flora, S.J.S., Pachauri, V., 2010. Chelation in metal intoxication. Int. J. Environ. Res. Public Health 7, 2745-2788.

Fournier, G.P., Gogarten, J.P., 2008. Evolution of acetoclastic methanogenesis in Methanosarcina via horizontal gene transfer from cellulolytic Clostridia. J. Bacteriol. 190, 1124-1127.

Gelperina, S., Kisich, K., Iseman, M.D., Heifets, L., 2005. The potential advantages of nanoparticle drug delivery systems in chemotherapy of tuberculosis. Am. J. Respir. Crit. Care Med. 172, 1487-1490.

Grosser, A., Neczaj, E., 2016. Enhancement of biogas production from sewage sludge by addition of grease trap sludge. Energy Convers. Manag. 125, 301-308.

Hu, Q.H., Li, X.F., Du, G.C., Chen, J., 2008a. Effect of nitrilotriacetic acid on bioavailability of nickel during methane fermentation. Chem. Eng. J. 143, 111-116.

Hu, Q.H., Li, X.F., Liu, H., Du, G.C., Chen, J., 2008b. Enhancement of methane fermentation in the presence of Ni2+chelators. Biochem. Eng. J. 38, 98-104.

Khoshnevisan, B., Tsapekos, P., Alvarado-Morales, M., Angelidaki, I., 2018. Process performance and modelling of anaerobic digestion using source-sorted organic 
household waste. Bioresour. Technol. 247, 486-495.

Ko, J.H., Wang, N., Yuan, T., Lü, F., He, P., Xu, Q., 2018. Effect of nickel-containing activated carbon on food waste anaerobic digestion. Bioresour. Technol. 266, 516-523.

Miao, H., Lu, M., Zhao, M., Huang, Z., Ren, H., Yan, Q., Ruan, W., 2013. Enhancement of Taihu blue algae anaerobic digestion efficiency by natural storage. Bioresour. Technol. 149, 359-366.

Prakash, D., Wu, Y., Suh, S.J., Duin, E.C., 2014. Elucidating the process of activation of methyl-coenzyme M reductase. J. Bacteriol. 196, 2491-2498.

Romero-Güiza, M.S., Vila, J., Mata-Alvarez, J., Chimenos, J.M., Astals, S., 2016. The role of additives on anaerobic digestion: A review. Renew. Sustain. Energy Rev. 58, 14861499.

Roussel, J., van Hullebusch, E., Esposito, G., Mucha, A.P., Fermoso, F.G., Collins, G., 2018. Trace element supplementation as a management tool for anaerobic digester operation: benefits and risks. IWA Publishing. https://doi.org/10.2166/9781780409429

Serrano, A., Pinto-Ibieta, F., Braga, A.F.M., Jeison, D., Borja, R., Fermoso, F.G., 2017. Risks of using EDTA as an agent for trace metals dosing in anaerobic digestion of olive mill solid waste. Environ. Technol. (United Kingdom) 38, 3137-3144.

Tsapekos, P., Kougias, P.G., Kuthiala, S., Angelidaki, I., 2018. Co-digestion and model simulations of source separated municipal organic waste with cattle manure under batch and continuously stirred tank reactors. Energy Convers. Manag. 159, 1-6.

Tsapekos, P., Kougias, P.G., Vasileiou, S.A., Lyberatos, G., Angelidaki, I., 2017. Effect of micro-aeration and inoculum type on the biodegradation of lignocellulosic substrate. Bioresour. Technol. 225, 246-253.

Vintiloiu, A., Boxriker, M., Lemmer, A., Oechsner, H., Jungbluth, T., Mathies, E., Ramhold, D., 2013. Effect of ethylenediaminetetraacetic acid (EDTA) on the bioavailability of trace elements during anaerobic digestion. Chem. Eng. J. 223, 436-441.

Yu, D., Li, C., Wang, L., Zhang, J., Liu, J., Wei, Y., 2016. Multiple effects of trace elements on methanogenesis in a two-phase anaerobic membrane bioreactor treating starch wastewater. Appl. Microbiol. Biotechnol. 


\section{Figures}
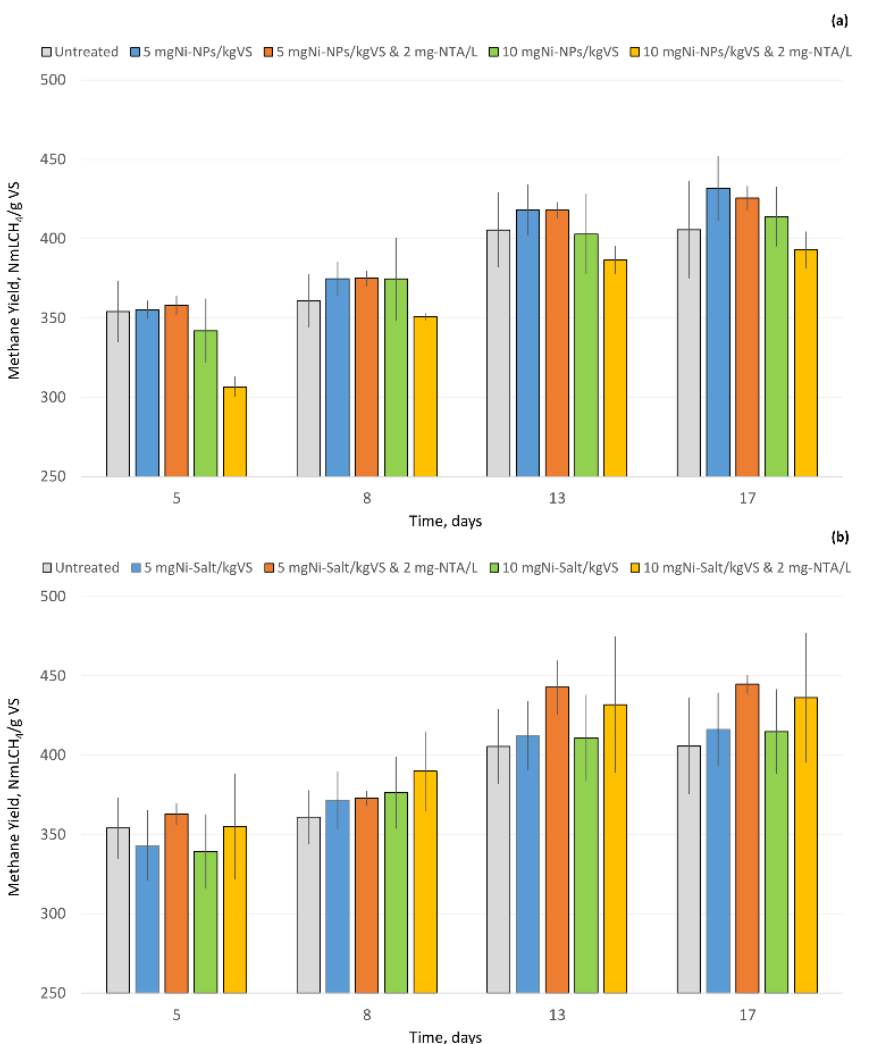

Fig. 1. Effects of spiked $\mathrm{Ni}$ in the form of a) $\mathrm{NPs}$ and b) $\mathrm{NiCl}_{2} \cdot 6 \mathrm{H}_{2} \mathrm{O}$ on accumulated methane yield over time

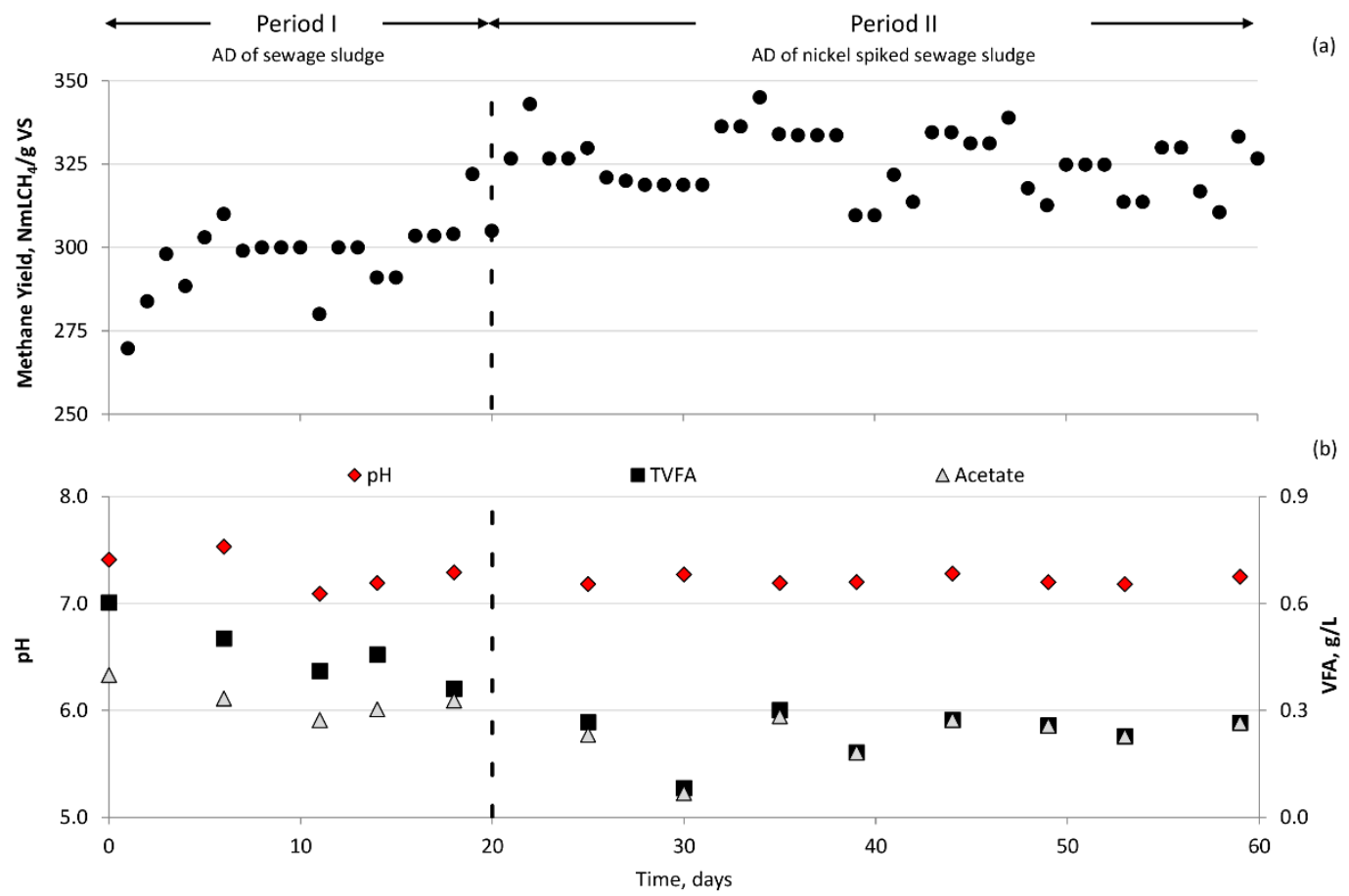

Fig. 2. Continuous mode operation: a) methane yield and b) pH-VFA changes over time 


\section{Tables}

Table 1. Physicochemical characteristics affected by different Ni addition strategies

\begin{tabular}{|c|c|c|c|c|c|}
\hline Characteristics & pH & $\begin{array}{c}\text { Alkalinity, } \\
\mathbf{g}_{\mathrm{CaCO} 3} / \mathbf{L}\end{array}$ & $\begin{array}{l}\text { COD, } \\
\text { g/L }\end{array}$ & $\begin{array}{c}\text { Acetate, } \\
\text { mg/L }\end{array}$ & $\begin{array}{l}\mathrm{CH}_{4} \text { yield, } \\
\mathrm{NmL} / \mathrm{gVS}\end{array}$ \\
\hline Untreated & 7.24 & $4.74 \pm 0.20$ & $23.82 \pm 0.20$ & $36.23 \pm 1.81$ & $406 \pm 34$ \\
\hline $5 \mathrm{mgNi}-\mathrm{NPs} / \mathrm{kgVS}$ & 7.32 & $4.81 \pm 0.22$ & $20.73 \pm 0.31$ & $15.11 \pm 0.76$ & $414 \pm 16$ \\
\hline $5 \mathrm{mgNi}-\mathrm{NPs} / \mathrm{kgVS} \& 2 \mathrm{mg}-\mathrm{NTA} / \mathrm{L}$ & 7.35 & $4.78 \pm 0.20$ & $23.13 \pm 0.08$ & $15.11 \pm 0.76$ & $414 \pm 21$ \\
\hline $10 \mathrm{mgNi}-\mathrm{NPs} / \mathrm{kgVS}$ & 7.35 & $4.77 \pm 0.19$ & $22.48 \pm 0.61$ & $15.21 \pm 0.76$ & $426 \pm 2$ \\
\hline $10 \mathrm{mgNi}-\mathrm{NPs} / \mathrm{kgVS} \& 2 \mathrm{mg}-\mathrm{NTA} / \mathrm{L}$ & 7.34 & $4.72 \pm 0.22$ & $23.00 \pm 0.24$ & $12.19 \pm 0.61$ & $393 \pm 12$ \\
\hline $5 \mathrm{mgNi}-\mathrm{Salt} / \mathrm{kgVS}$ & 7.37 & $4.78 \pm 0.23$ & $23.80 \pm 0.41$ & $15.66 \pm 0.78$ & $416 \pm 23$ \\
\hline $5 \mathrm{mgNi}-\mathrm{Salt} / \mathrm{kgVS} \& 2 \mathrm{mg}-\mathrm{NTA} / \mathrm{L}$ & 7.25 & $4.68 \pm 0.18$ & $21.27 \pm 0.13$ & $20.84 \pm 1.04$ & $415 \pm 29$ \\
\hline $10 \mathrm{mgNi}-\mathrm{Salt} / \mathrm{kgVS}$ & 7.38 & $4.86 \pm 0.24$ & $21.76 \pm 0.26$ & $20.17 \pm 1.01$ & $445 \pm 9$ \\
\hline $10 \mathrm{mgNi}-\mathrm{Salt} / \mathrm{kgVS} \& 2 \mathrm{mg}-\mathrm{NTA} / \mathrm{L}$ & 7.35 & $4.71 \pm 0.21$ & $25.64 \pm 1.23$ & $18.60 \pm 0.93$ & $436 \pm 42$ \\
\hline
\end{tabular}

